\title{
Leah Adler: A Tribute
}

\section{Pearl Berger \\ Yeshiva University Dean of Libraries, Emerita}

\begin{abstract}
Shortly after Leah Adler's untimely passing, I visited Yeshiva University's Mendel Gottesman Library. I felt that I must pay a condolence call to the Library itself, as well as to the people who worked closely with Leah for so many years. Yeshiva University, along with the profession of Judaic librarianship, had just lost a star.
\end{abstract}

I had the privilege of working with Leah at YU for over thirty years. She was attending library school when she joined the staff and rose, relatively quickly, to the position of Head Librarian. She embodied a rare combination of professional and personal qualities that enabled her to reach the top of her profession while maintaining close supportive relationships with her colleagues. Leah was brilliant and a perfectionist. She took time to understand and master new protocols, systems, and techniques, and proceeded to implement them with clarity and precision. She was the library go-to person with language questions as she was proficient in classical and European languages. And let's not take for granted her Torah knowledge, a sine qua non for the Mendel Gottesman Library.

Leah tended to be quiet and unassuming, but she showed strength when it was warranted and she inspired confidence. Her fellow staff members sought her advice on work related as well as personal matters.

Leah was a truly refined human being-an eydeler mentsh in the fullest sense. Yehi zichrah baruch.

The tribute is a slightly edited version of the one originally posted online on the Yeshiva University blog (May 10 , 2019), "Leah Adler - In Memoriam and a Tribute,” https://blogs.yu.edu/library/2019/05/10/leah-adler-in-memoriam. 